\title{
Heat emission coefficients of a combined oil separator
}

\author{
Bagaudin Khamidovich Gaitov \\ Department of Electrical Engineering and Electrical \\ Machines \\ Kuban State Technological University \\ Krasnodar, Russia \\ e-mail: kkllev1@mail.ru \\ Lev Efimovich Kopelevich \\ Department of Electrical Engineering and Electrical \\ Machines \\ Kuban State Technological University \\ Krasnodar, Russia line \\ e-mail: kkllev@mail.ru
}

\author{
Yakov Mikhailovich Kashin \\ Department of Electrical Engineering and Electrical \\ Machines \\ Kuban State Technological University \\ Krasnodar, Russia \\ e-mail: jlms@mail.ru \\ Vladislav Anatolievich Kim \\ Department of Electrical Engineering and Electrical \\ Machines \\ Kuban State Technological University \\ Krasnodar, Russia \\ e-mail: vladk-kub@mail.ru
}

Abstract. The paper studies the heat emission coefficient of combined oil separator.

The work considers a mathematical model of the temperature field of the combined oil separator. The work is aimed at investigation and analysis of heat emission coefficients of the combined oil separator at oil and gas facilities.

The article describe the combined oil separator with motorseparator scheme that uses the losses in the rotor-drum of the separator as heating losses for heating separation product in the separator drum, and uses energy losses liberated by the core and winding of the separator motor stator for preliminary heating of the separation product; in addition, the heat emission coefficients of the combined oil separator are considered which are necessary for making up the machine temperature field to improve the machine build and reduce energy consumption.

Keywords: separator, mathematical model, heat emission coefficient.

\section{INTRODUCTION}

The present can be called the age of plastic and neon; however, despite the continuous progress of science and technology, we-similarly to the previous century-depend on oil in terms of energy source and raw materials for organic chemistry. Nevertheless, oil extracted from beneath the ground, as a rule, contains gas called associated gas, produced water, mineral salts, various mechanical impurities. Along with each ton of oil, $50-100 \mathrm{~m}^{3}$ of associated (oil) gas and 200-300 kg of water with dissolved salts are also extracted. Before the transportation and oil processing, the gas should be separated from the oil [1]. Oil-gas (oil-water-gas) mixture from wells is first separated under high pressure at the first separation stage, where the major part of gas is liberated.
Then, oil is separated under moderate and low pressure and finally degassed. To produce oil of necessary quality, at one of the separation stages oil is heated; this stage is called hot separation [2]. At a temperature of about $120{ }^{\circ} \mathrm{C}$ and in the presence of demulsificators, the content of water and mineral salts decreases, and third-stage separation gas liberates [3].

Conditionally, the hot separation stage can be represented as the following processing cycle: oil-water-gas mixture -> heater $\rightarrow$ separator $\rightarrow$ refined oil.

In the Department of Electrical Engineering and Electrical Machines at the Kuban State Technological University, a setup for oil separation [4, 5] (Fig. 1) was developed and constructed within the work on optimization of energy consumption by electric machines at oil and gas production fields.

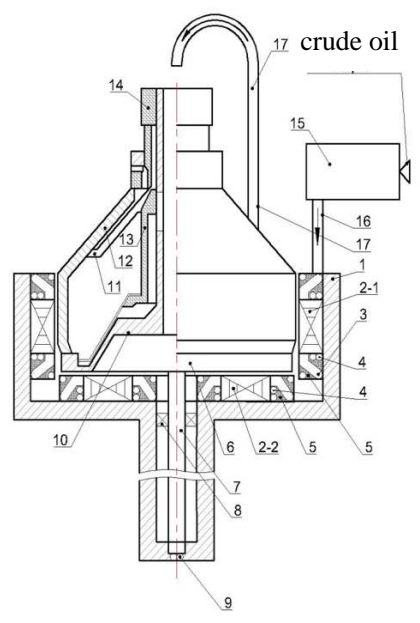

Fig. 1. Oil separator 
The oil separator consists of separator case 1, electric motor stator mounted in it comprising two parts (cylindrical part 2-1, axial part 2-2) with winding 3 of two stator parts which front part is surrounded by pipes 4 filled with compound 5, separator drum 6 that simultaneously plays the role of the electric motor rotor, which is rigidly connected with shaft 7, oil heater 15 and connecting pipes 16 and 17 . Shaft 7 is mounted in bearing assemblies 8 and 9. Separator drum 6 consists of base 10 with central pipe, separation disks 11 , cap 12, disk support 13 and clamping ring 14. Connection pipe 16 connects oil heater 15 with the inlet of pipes 4 , while connection pipe 17 connects outlet of pipes 4 with the internal part of separator drum 6.

Fig. 2 depicts the scheme of studied separator motor (SM). The studied motor is an approximate physical model of machine motor, which smooth massive rotor is the working part with canals passing the product which simultaneously plays the role of coolant. The front parts of the stator winding and external part of the stator core are wound by the pipeline passing the product (coolant); in Fig. 2, arrows denote its movement scheme.

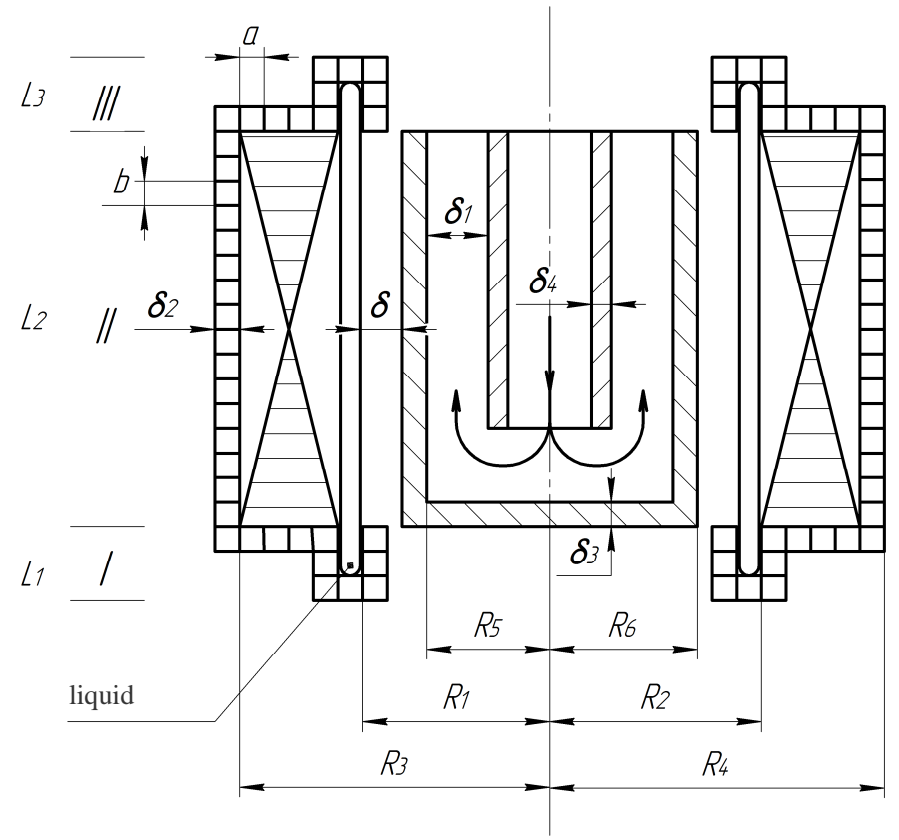

Fig. 2. SM model for studying heat transition processes.

Eq. (1) represents the mathematical model of the combined oil separator temperature field at different sections of the structure. Index " $\mathrm{S}_{1}$ " corresponds to the stator phase windings, index $" \mathrm{~S}_{2}$ " corresponds to the stator windings in which equivalent eddy currents flow; " $r$ " means rotor.

$$
\left\{\begin{array}{c}
C_{w} \rho_{w} \frac{\partial T_{s 1}}{\partial t}=\lambda_{w r}\left(\frac{\partial^{2} T_{s 1}}{\partial r^{2}}+\frac{1}{r} \frac{\partial T_{s 1}}{\partial r}\right)+\left(\frac{\partial^{2} T_{s 1}}{\partial Z^{2}}\right) \lambda_{w Z}+\frac{R_{s 1}}{V_{s 1}}\left(i_{s 1 \mathcal{L}}^{2}+i_{s 1 \beta}^{2}+i_{s 1 \gamma}^{2}\right) \\
R_{1} \leq r \leq R_{2} \quad 0 \leq Z \leq L_{5} \\
C_{s} \rho_{s} \frac{\partial T_{s 2}}{\partial t}=\lambda_{s r}\left(\frac{\partial^{2} T_{s 2}}{\partial r^{2}}+\frac{1}{r} \frac{\partial T_{s 2}}{\partial r}\right)+\left(\frac{\partial^{2} T_{s 2}}{\partial Z^{2}}\right) \lambda_{s z}+\frac{R_{s 2}}{V_{s 2}} e^{r \sqrt{2 \mu_{s} Y_{s 2} f_{0}}}\left(i_{s 2 \mathcal{L}}^{2}+i_{s 2 \beta}^{2}+i_{s 2 \gamma}^{2}\right) \\
R_{2} \leq r \leq R_{3} \quad L_{1} \leq Z \leq L_{2} \\
C_{r} \rho_{r} \frac{\partial T_{r}}{\partial t}=\lambda_{r}\left(\frac{\partial^{2} T_{r}}{\partial r^{2}}+\frac{1}{r} \frac{\partial T_{r}}{\partial r}\right)+\left(\frac{\partial^{2} T_{r}}{\partial Z^{2}}\right)+\frac{R_{r}}{V_{r}} e^{r \sqrt{2 \mu_{r} f_{0} S_{r} \gamma_{r}}}\left(i_{r \mathcal{L}}^{2}+i_{r \beta}^{2}+i_{r \gamma}^{2}\right) \\
R_{5} \leq r \leq R_{6} \quad L_{1} \leq Z \leq L_{2}
\end{array}\right.
$$

where $C_{w}, C_{s}, C_{r}$ are specific heat capacities of the stator phase winding, stator core and rotor;

$\rho_{w}, \rho_{s}, \rho_{r}$ are densities of the material of the stator phase winding, stator core and rotor;

$T_{s 1}, T_{s 2}, T_{r}$ are instant temperatures;

$\lambda_{w r}, \lambda_{w z}, \lambda_{s r}, \lambda_{s z}, \lambda_{r}$ are heat conductivity coefficients of phase winding and stator core along the axes and rotor; $\mathrm{r}, \mathrm{z}$ are cylindrical coordinates;

$R_{s 1}, R_{s 2}, R_{r}$ are active resistances of stator and rotor windings along the axes, $\mathcal{L}, \beta, \gamma$ respectively depending on temperature $T_{s 1}, T_{s 2}, T_{r}$;

$V_{r}, V_{s 1}, V_{s 2}$ is the volume of the machine unit under investigation;

$i_{s 1 \mathcal{L}}, i_{s 1 \beta}, i_{s 1 \gamma}, i_{s 2 \mathcal{L}}, i_{s 2 \beta}, i_{s 2 \gamma}, i_{r \mathcal{L}}, i_{r \beta}, i_{r \gamma}$ are currents in the stator and rotor along the axes $\mathcal{L}, \beta, \gamma$;

$L_{s 1}, L_{s 2}, L_{r}$ are full inductivities of the stator and rotor windings along the axes $\mathcal{L}, \beta, \gamma$;

$\mu_{s}, \mu_{r}$ is relative magnetic permittivity of core steel of stator and rotor;

$f_{0}$ is supply frequency;

$\mathrm{S}$ is slip;

$\gamma_{s 1}, \gamma_{r}$ are specific temperature-dependent material conductivities.

In fact, the boundary conditions between different machine units, product (coolant) and environment are determined by known heat transfer rules [6].

For instance, on the boundary between the slot part of winding and stator core act boundary conditions of the fourth kind.

On the boundary between the stator core and coolant, and between machine units and environment act boundary conditions of the third kind.

According to the afore mentioned, the boundary conditions are as follows:

$$
\begin{aligned}
& \lambda_{w r}{\frac{\partial T_{s 1}(r, z, t)}{\partial r}}_{r=R_{2}}=\lambda_{s r}{\frac{\partial T_{s 2}(r, z, t)}{\partial r} r=R_{2}}^{\prime}, \\
& T_{s 1}(r, z, t)_{r=R_{2}}=T_{s 2}(r, z, t)_{r=R_{2}} \text {, } \\
& L_{1} \leq Z \leq L_{2} \\
& \lambda_{r}{\frac{\partial T_{r}(r, Z, t)}{\partial r}}_{r=R_{5}}=\lambda_{w r}{\frac{\partial T_{s 1}(r, z, t)}{\partial r}}_{r=R_{1}}=\mathcal{L}_{13}\left(\omega_{r}\right)\left(T_{r}-T_{s 1}\right) \text {, } \\
& L_{1} \leq Z \leq L_{2}
\end{aligned}
$$

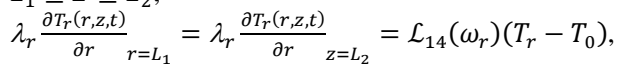

$$
\begin{aligned}
& R_{5} \leq r \leq R_{6} \\
& \lambda_{l}{\frac{\partial T_{l 6}(z, t)}{\partial z}{ }_{z=L_{1}}}=\mathcal{L}_{5}\left(\omega_{r}, r\right)\left(T_{l 10}-T_{0}\right) \\
& 0 \leq r \leq R_{5} \\
& S_{l} C_{l} \rho_{l}\left(\frac{\partial T_{l 1}}{d t}+V_{l} \frac{\partial T_{l 1}}{d Z}\right)=\mathcal{L}_{1} \Pi_{1}\left(T_{s 1}-T_{l 1}\right)+\mathcal{L}_{2} \Pi_{2}\left(T_{l 1}-T_{0}\right), \\
& R_{1} \leq r \leq R_{2}, \quad 0 \leq Z \leq L_{1}, \quad\left(T_{0}=T_{l 1}\right)_{z=0} \text {; } \\
& T_{l 1} /_{Z}=L_{1}=T_{l 2} / Z=L_{1}^{*} \\
& S_{l} C_{l} \rho_{l}\left(\frac{\partial T_{l 2}}{d t}+V_{l} \frac{\partial T_{l 2}}{d z}\right)=\mathcal{L}_{3} \Pi_{3}\left(T_{s 2} / Z=L_{1}-T_{l 2}\right)+\mathcal{L}_{4} \Pi_{4}\left(T_{l 2}-T_{0}\right), \\
& R_{3} \leq r \leq R_{2} \\
& T_{l 2} / Z=L_{1}=T_{l 3} / Z=L_{1} ; \\
& S_{l} C_{l} \rho_{l}\left(\frac{\partial T_{l 3}}{d t}+V_{l} \frac{\partial T_{l 3}}{d Z}\right)=\mathcal{L}_{12} \Pi_{5}\left(T_{s 2} / r=R_{3}-T_{l 3}\right)+\mathcal{L}_{6} \Pi_{6}\left(T_{l 3}-T_{0}\right) \\
& L_{1} \leq Z \leq L_{2} \\
& T_{l 3} /_{Z}=L_{2}=T^{l 4} / Z=L_{2} ; \\
& S_{l} C_{l} \rho_{l}\left(\frac{\partial T_{l 4}}{d t}+V_{l} \frac{\partial T_{l 4}}{d z}\right)=\mathcal{L}_{3} \Pi_{7}\left(T_{s 2} / Z=L_{2}-T_{l 4}\right)+\mathcal{L}_{8} \Pi_{8}\left(T_{l 4}-T_{0}\right) ;
\end{aligned}
$$


$R_{3} \leq r \leq R_{2}$

$T_{l 4} / Z=L_{2}=T_{l 5} / Z=L_{2} ;$

$S_{l} C_{l} \rho_{l}\left(\frac{\partial T_{l 5}}{d t}+V_{l} \frac{\partial T_{l 5}}{d z}\right)=\mathcal{L}_{9} \Pi_{9}\left(T_{s 1}-T_{l 5}\right)+\mathcal{L}_{10} \Pi_{10}\left(T_{l 5}-T_{0}\right) ;$

$L_{2} \leq Z \leq L_{3}$

$R_{1} \leq r \leq R_{2}$

$T_{l 5} / Z=L_{3}=T_{l 6} / Z=L_{1} ;$

$S_{l} C_{l} \rho_{l}\left(\frac{\partial T_{l 6}}{d t}+V_{l} \frac{\partial T_{l 6}}{d z}\right)=\mathcal{L}_{11}\left(\omega_{r}, z\right) \cdot\left(T_{r} / r=R_{5}-T_{l 6}\right)$,

$L_{1} \leq Z \leq L_{2}$;

$\lambda_{c 2 r}{\frac{\partial T_{s 2(r, z, t)}}{\partial Z}{ }_{r=R_{3}}}=\mathcal{L}_{12}\left(T_{s 2}-T_{l 3}\right)$,

$L_{1} \leq Z \leq L_{2}$

$\lambda_{c 2 z} \frac{\partial T_{c 2(r, z, t)}}{\partial Z}=\mathcal{L}_{8}\left(T_{c 2}-T_{l 2}\right)$,

$R_{2} \leq r \leq R_{3}$

$\lambda_{c 2 z}{\frac{\partial T_{c 2(r, z, t)}}{\partial z}}_{z=L_{2}}=\mathcal{L}_{7}\left(T_{c 2}-T_{l 4}\right)$,

$R_{2} \leq r \leq R_{3}$

$\lambda_{r}{\frac{\partial T_{r(r, z, t)}}{\partial r}}_{r=R_{5}}=\mathcal{L}_{11}\left(\omega_{r}, z\right)\left(T_{r}-T_{l 6}\right)$,

$L_{1} \leq Z \leq L_{2}$

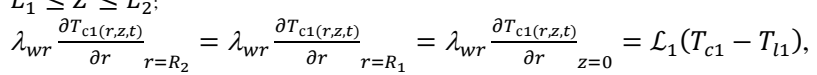

$0 \leq Z \leq L_{1}, R_{1} \leq r \leq R_{2}$;

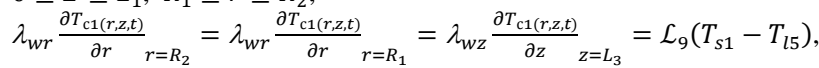

where $\mathrm{C}_{\mathrm{li}}$ and pli are specific heat capacity and density of the liquid;

$\mathrm{V}_{1}$ is the liquid velocity in the channel;

$\mathcal{L}_{1}, \mathcal{L}_{2}, \mathcal{L}_{3}, \mathcal{L}_{4}, \mathcal{L}_{6}, \mathcal{L}_{7}, \mathcal{L}_{8}, \mathcal{L}_{9}, \mathcal{L}_{10}, \mathcal{L}_{12}, \mathcal{L}_{13}$ are heat transfer coefficients;

$\mathcal{L}_{5}, \mathcal{L}_{11}, \mathcal{L}_{14}$ are heat emission coefficients;

$S_{l}$ is the cross-section of the channel for the liquid;

$\Pi_{1}, \ldots, \Pi_{10}$ are perimeters of the heat contact of the surface and liquid;

$T_{l 1} \ldots, T_{l 6}$ are instant liquid temperatures. The heat conductivity coefficient of the stator winding $\lambda_{w r}, \lambda_{w z}$ is determined by known equations $[6,7]$, as an equivalent heat conductivity coefficient $\lambda_{w}$ of ordered windings from round wires.

The value of $\lambda_{w}$ depends on the wire diameter and its insulation thickness, scheme of winding laying in the slot, heat conductivity coefficients of the wire, insulation and insulation gaskets.

The heat conductivity coefficient of core-lamination stack across the sheets $\left(\lambda_{s Z}\right)$ is calculated using [8] and depends on the thickness of the steel lamination and insulation between the sheets, heat conductivity coefficients of steel and insulation.

The heat coefficients of the rotor material $\left(\lambda_{r}\right)$ and electrical steel of the stator pack along the sheets $\left(\lambda_{s r}\right)$ and is determined from references $[8,10,11]$.

The specific heat capacities and densities of liquid, materials of rotor and stator core are to be chosen from a reference book [8].

The specific heat capacity of stator winding $C_{M}$ is determined as equivalent heat capacity.

$$
C_{e q}=C_{w}=\frac{\left(C_{c o p} V_{c o p}+C_{a i r} V_{a i r}+C_{i n s} V_{i n s}\right)}{V},
$$

where $C_{\text {cop }}, C_{\text {sir }}, C_{\text {ins }}$ are specific heat capacities of copper, air and insulation;
$V_{\text {cop }}, V_{\text {air }}, V_{\text {ins }}$ is the volume occupied by copper wires, air and insulation in the total volume $V$.

External heat exchange conditions (boundary conditions) can vary depending on the coupling of machine units and environment. The machine parts with environment can be coupled through one of the boundary conditions: first, second or third kind. On such statement of the problem as in the present work, one can use either boundary conditions of first kind $\mathrm{T}(\mathrm{r}, \mathrm{z}, \mathrm{t})$ or boundary conditions of third kind.

$$
-\lambda_{\mathrm{i}} \frac{d T_{\mathrm{i}}}{d n}=\alpha\left(T_{\mathrm{i}}-T_{\mathrm{j}}\right) .
$$

where $\mathrm{n}$ is a normal to the surface;

$T_{i}$ is the temperature of sought body;

$\mathrm{T}_{\mathrm{j}}$ is the temperature of environment;

$\alpha$ is heat emission coefficient.

The usage of boundary conditions of the first kind facilitates problem solution; however, it requires experimental determination of the boundary conditions. The latter is not always possible, which in current problem does not allow comparing experimental and computation data. In this connection, the solution of permanent problem requires boundary conditions of the third kind.

Thus, to solve the stated problem, one needs to determine the heat emission coefficients between machine parts and ambient air, and between machine parts and flowing liquid, i.e. coolant (product).

The heat emission coefficients depend on physical properties of gas and liquid, characterized by their viscosity coefficient, heat conductivity coefficient $\lambda$, substance density $\rho$, volumetric expansion coefficient $\beta$, gravitational acceleration $\mathrm{g}$, dimensions of a body, liquid and gas flow regimes (hereinafter, the values with index $a$ correspond to air, and $l$ corresponds to liquid). For the calculation of the heat emission coefficients, the following assumptions were made: the thermophysical properties of the system do not depend on temperature; the rotor is considered to have ideally smooth surface; the losses in the machine ends are not accounted; all considered machine parts are characterized by strong thermal bounds; the front parts of the stator winding have no bend; every coil of the cooling pipe with wall thickness $\delta_{2}$ and crosssection $a^{*} b$ (Fig. 2) is considered to touch the stator core by one side and with air by the other side, and does not touch neighboring coils; in the technological part of the rotor, the heat transfer though wall $\delta_{4}$ is negligible; when determining the kind of liquid flow though the stator cooling pipe, the pipe walls are considered as cylinders in relation to the pipe axis; when determining the heat transfer coefficient, the inner wall is considered to by cylindrical in relation to the machine axis, while the external one has rectangular profile; the lifting force of the liquid arising when it flows around the stator core ends is neglected; the heat emission from the ends of winding overhangs is neglected; the change in the heat emission coefficient in bent pipes is not considered; the liquid does not get into cooling pipe with stabilized flow; there is no turbulent liquid turn regime near $\delta_{3}$. 


\section{DETERMINING THE HEAT EMISSION COEFFICIENT FOR STATOR COOLING PIPE}

When determining the heat emission coefficients for this region of the asynchronous motor one should consider that the equations envisage heat interaction of the stator winding and core with the liquid through the cooling pipe. Hence, for this case, coefficient $\alpha$ for equation (4) should be the heat transfer coefficient.

The heat transfer coefficients from stator (stator winding and core) to liquid and from liquid to air can be determined using the technique from [9]:

$$
\begin{gathered}
\alpha_{1}=\frac{1}{\left(\frac{1}{2 \lambda p i p e} \ln \frac{R^{i} 1}{R^{i} 2}+\frac{1}{2 \alpha^{\prime} R i 1}\right) i} ; \\
\alpha_{2}=\frac{1}{\left(\frac{1}{\alpha^{\prime \prime}}+\frac{\delta 2}{\lambda p i p e}+\frac{1}{\alpha 1}\right)} .
\end{gathered}
$$

where $\lambda_{\text {pipe }}$ is the coefficient of material heat conductivity which the pipe is made from;

$\mathrm{L}_{\mathrm{i}}, \mathrm{R}_{\mathrm{i} 1}, \mathrm{R}_{\mathrm{i} 2}, \delta_{2}$ are dimensions;

$\alpha^{\prime}, \alpha^{\prime \prime}$ are heat emission coefficients determined from criterion equations.

Therewith,

$$
\begin{aligned}
& R_{i 1}=R_{3}+\delta_{2} ; \\
& R_{i 1}=\left\{\begin{array}{l}
R_{2}+\delta_{2} \\
R_{1}-\delta_{2}
\end{array} ;\right. \\
& R_{i 2}=L_{1}-\delta_{2} ; \\
& R_{i 2}=L_{2}+\delta_{2} .
\end{aligned}
$$

Equation (7a) determines the heat transfer coefficient on section II, eq. (7b) is used on sections I and III, eq. (7c) is used on section I of stator core ends, eq. (7d) is used on section III of stator core ends.

Heat emission coefficients $\alpha^{\prime}$, depending on the machine section, corresponds to coefficients $\alpha_{1}$ on section $1, \alpha_{3}$ on section $R_{2}-R_{3}, \alpha_{12}$ on section $2, \alpha_{7}$ on section $R_{2}-R_{3}$ (outflow of the coolant from the stator), $\alpha_{9}$ on section 3 . Where $\alpha_{1}=\alpha_{9}, \alpha_{3}=\alpha_{7}$. Due to the assumption of negligible lifting force of the liquid when it flows around the core ends, $\alpha_{1}=$ $\alpha_{3}=\alpha_{12}=\alpha_{7}$.

Calculation of coefficients $\alpha^{\prime}, \alpha^{\prime \prime}$ requires taking into account the regime of liquid flow (laminar or turbulent), running through the pipe, which according to [9] is made by preliminary calculation of Reynolds number $(\mathrm{Re})$ :

At $18500 \cdot\left(\frac{2 a b}{a+b}\right)^{0,28} \leq R e$, the flow regime is laminar.

At $18500 \cdot\left(\frac{2 \mathrm{ab}}{\mathrm{a}+\mathrm{b}}\right)^{0,28}>R e$, the flow regime is turbulent.

$$
R e=\frac{v \cdot d}{v},
$$

where $\mathrm{v}$ is the medium flow velocity;

$\mathrm{d}$ is dimensions;

$v$ is medium viscosity.

Thus, the heat emission coefficient $\alpha_{1}$ is determined as

$$
\alpha^{\prime}=\frac{0,021 \lambda_{l}(a+b)^{0.2} P_{r l}{ }^{0.48} \partial^{0.8} \varepsilon}{2^{0.2} \cdot a \cdot b \cdot v_{l}^{0,8} \cdot \rho^{0.8}} ;
$$

where $\mathrm{G}$ is liquid mass flow;

$\mathrm{P}_{\mathrm{rl}}$ is liquid Prandtl number;

$\varepsilon$ is coefficient factoring the liquid flow kind;

$a$ and $b$ are dimensions of pipe cross-section.
For laminar flow $\varepsilon=1$; for turbulent

$$
\varepsilon=1+1.8 \cdot \frac{2 a b}{(a+b) R}
$$

where $\mathrm{R}$ is equivalent dimensions of pipe cross-section, which is chosen depending on the section (I, II, III). When determining the heat emission coefficient for pipe to air, one can use an equation from [9] derived from the solution of criterion equations:

$$
\alpha^{\prime \prime}=\frac{\lambda_{\text {air }} 0.6 \cdot\left(G_{\text {rair }} \cdot P_{\text {rair }}\right)^{0.25}}{2 R}
$$

where $\alpha_{\text {air }}$ is air heat conductivity coefficient; $\mathrm{G}_{\text {rair }}\left(\mathrm{g}, \beta, \rho_{\text {air }}, \mathrm{v}_{\text {air }}, \mathrm{R}\right), \mathrm{P}_{\text {rair }}$ are respectively Grashof number and Prandtl number for air.

Fig. 3 plots dependencies $\alpha_{1}=f(G)$ and $\alpha_{2}=f(G)$ (liquid is water). The calculations were made for the following pipe materials: copper, steel, aluminium. Obviously, the heat emission coefficients demonstrate no significant dependence on the pipe material.

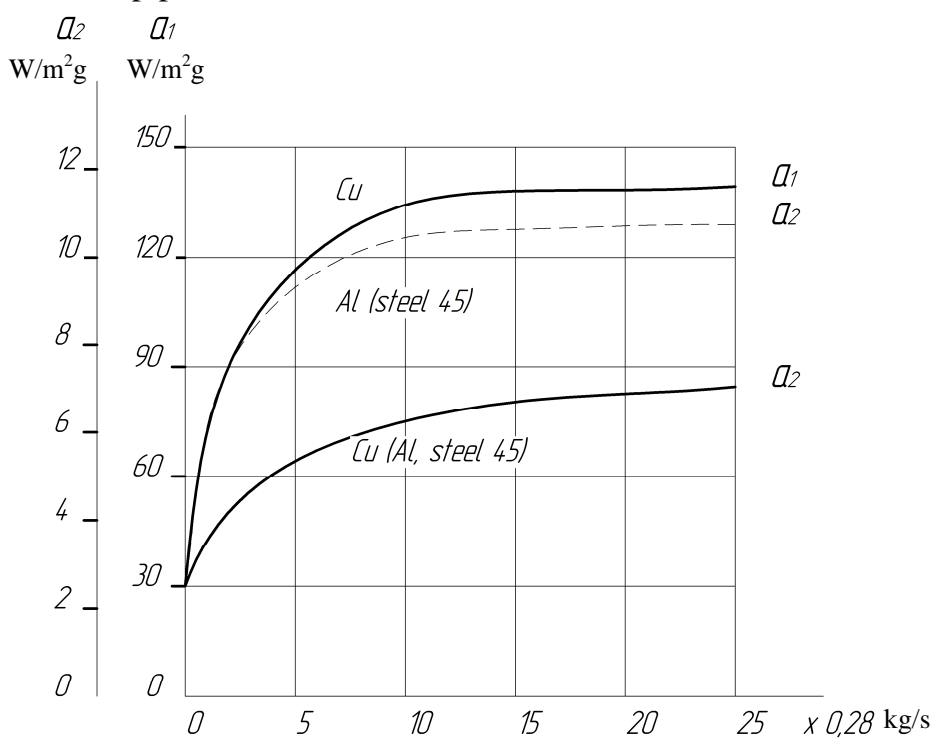

Fig. 3. Dependencies of heat emission coefficient at stator-liquid boundary on flow head

\section{DETERMINATION OF HEAT EMISSION COEFFICIENT THROUGH AIR GAP BETWEEN STATOR AND ROTOR}

Since for such type of investigated asynchronous motor it is important to recycle heat liberated in the machine for technological needs, let us consider the processes occurring in the machine gap without axial movement of air.

There is a number of methods for determining the heat emission coefficient of a rotating rotor $[8,10,11]$. In [8], only the rotor rpm and geometry are considered. A drawback of this method is that it does not account the size of the air gap and free air convection.

Method from [11] only considers the size of air gap $\delta$, but still does not account for free convection. A particular interest is in taking into account free convection in the machine air gap. This is even more necessary because up to some critical velocity $\omega_{\mathrm{cr}}$, the heat exchange in the gap occurs only through free convection. The critical velocity in the calculations without accounting free convection is determined as in [7]; 
when calculating free convection in the gap, it is calculated as in [8].

$$
\omega_{\text {кр }}=\frac{0,55 v_{\text {air }}}{R_{r}} \sqrt{\frac{G_{\text {rair }}}{P_{\text {rair }}}}
$$

where $\mathrm{R}_{\mathrm{r}}$ is rotor radius.

Then, at $\omega<\omega_{c r}$, the heat emission coefficient in the gap between stator and rotor is determined by free convection and calculated as

$$
\alpha_{13}=\frac{0.228\left(G_{\text {rair }} \cdot P_{\text {rair }}\right)^{0.25} \lambda_{\text {air }}}{2 \delta}
$$

At $\omega>\omega_{c r}$, the heat emission coefficient in the machine gap is determined by free and induced convection and calculated as

$$
\alpha_{13}=\frac{0.095\left[\left(\frac{R_{r} \omega_{r} \delta}{v_{\text {air }}}\right)^{2} \cdot 2+G_{\text {rair }}\right]^{0.35} \lambda_{\text {air }}}{2 \delta}
$$

when calculating the heat emission coefficient, the temperature of air heating is taken equal the temperature of air in the middle of the machine.

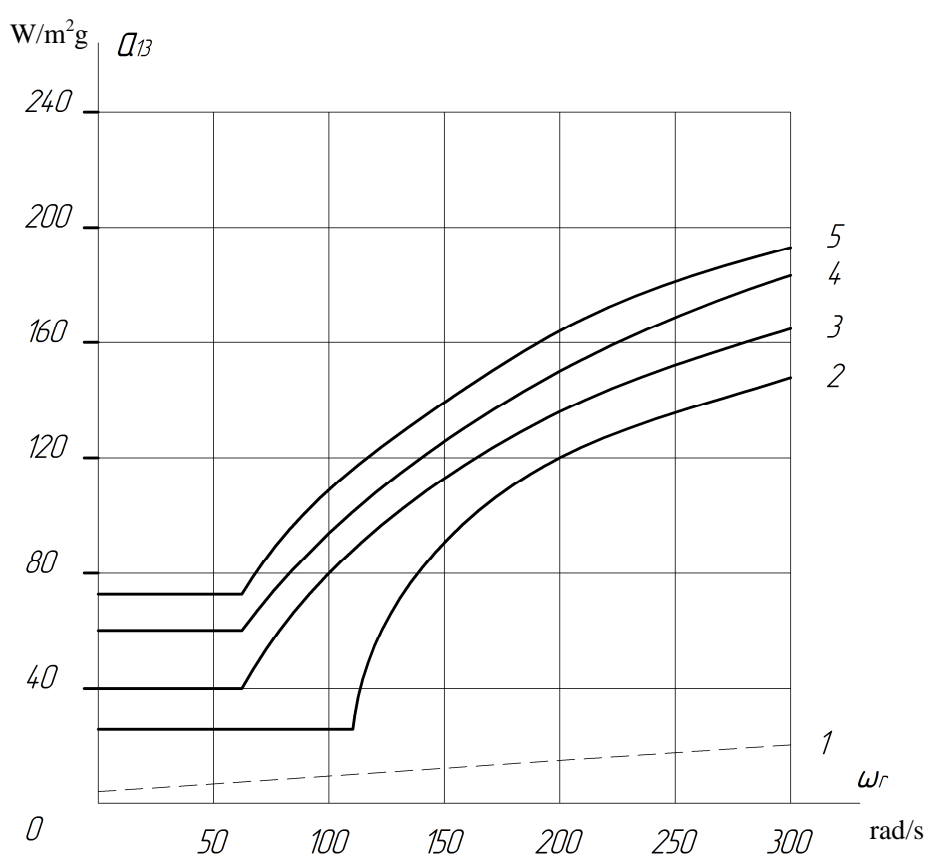

Fig. 4. dependencies of heat emission coefficient in asynchronous motor on rotor rpm: 1) not accounting for $\delta$ and free convection; 2) $\delta=0.015 \mathrm{~m}$ and not accounting for free convection; 3) $\delta=0.015 \mathrm{~m}$; 4) $\delta=0.001 \mathrm{~m}$; 5) $\delta=0.0005$ $\mathrm{m}$.

Fig. 4 depicts the dependencies of heat emission coefficient in asynchronous motor gap calculated for different gaps using three methods: with due consideration of free convection and air gap size, without considering free convection as in [11] and without considering free convection and air gap size.

The analysis of curves shows their appreciable divergence, which confirms the statement that the calculation of heat emission coefficient in air gap should take into account both free convection and air gap size.

\section{DETERMINATION OF HEAT EMISSION COEFFICIENT FROM ROTOR ENDS}

The stated problem envisages the solution in twodimensional geometrical region, which requires defining the regime of convective heat exchange of asynchronous motor rotor ends. To evaluate the regime, one needs determining the dependence of heat emission coefficient $\alpha_{14}$ for solid rotor part and heat emission coefficient $\alpha_{5}$ through rotor wall $\delta_{3}$ on its rpm and dimensions.

When determining $\alpha_{14}$, one can use method [6] which includes initial determination of heat emission regime (laminar and turbulent) through critical velocity $\omega_{\mathrm{cr}}$ at given rotor radius $R_{r}$ or through critical radius at given velocity.

$$
\begin{aligned}
& \omega_{c r}=\frac{3 \cdot 10^{5} \lambda_{\text {air }}}{R_{r}^{2}} ; \\
& R_{r c r}=\sqrt{\frac{3 \cdot 10^{5} \lambda_{\text {air }}}{\omega_{r}} .}
\end{aligned}
$$

Since we need to determine local heat emission coefficients, $\mathrm{R}_{\mathrm{rcr}}$ should be found at given rotor rpm.

At $R_{\mathrm{rcr}}<1.26 .\left(\omega_{\mathrm{r}}=320 \mathrm{rad} / \mathrm{s}\right)$, the heat emission coefficient does not depend on rotor radius and is determined from criterion equation for laminar regime.

$$
\alpha_{14}=0.22 \lambda_{\text {air }} \cdot P_{\text {rair }} 0.6 \sqrt{\frac{\omega_{r}}{v_{\text {air }}}}
$$

At $\mathrm{R}_{\mathrm{cr}} \geq 1.26 \mathrm{~m} \quad\left(\omega_{\mathrm{r}}=320 \mathrm{rad} / \mathrm{s}\right)$, the heat emission coefficient is determined from criterion equation for turbulent regime and depends on the rotor radius[11].

$$
\alpha_{14}=\frac{0.012 \lambda \cdot 8 \omega_{r}^{0.8} \cdot R_{r}{ }^{0.6} \cdot P_{r}{ }^{0.6}}{v_{b}{ }^{0.8}} \text {. }
$$

To determine the heat transfer coefficient $\alpha_{5}$, one should initially determine heat emission coefficient $\alpha_{5}$ 'from liquid to wall $\delta_{3}$. Here one should account for the assumption on neglecting the liquid twist near wall $\delta_{3} ; \alpha_{5}$, similarly to $\alpha_{14}$, is determined on the basis of condition [8]. Depending on $\omega_{\mathrm{cr}}$, $\alpha_{5}{ }^{\prime}$ is determined according to conditions of $[10,11]$, but instead of $\lambda_{\text {air }}, \mathrm{P}_{\text {rair }}, v_{\text {air }}$, one should use $\lambda_{\mathrm{l}}, \mathrm{P}_{\mathrm{rl}}, v_{\mathrm{l}}$. Heat transfer coefficient $\alpha_{5}$ is determined as

$$
\alpha_{5}=\frac{1}{\frac{1}{\alpha_{14}}+\frac{1}{\alpha_{5}}+\frac{\delta_{3}}{\lambda_{r}}} .
$$




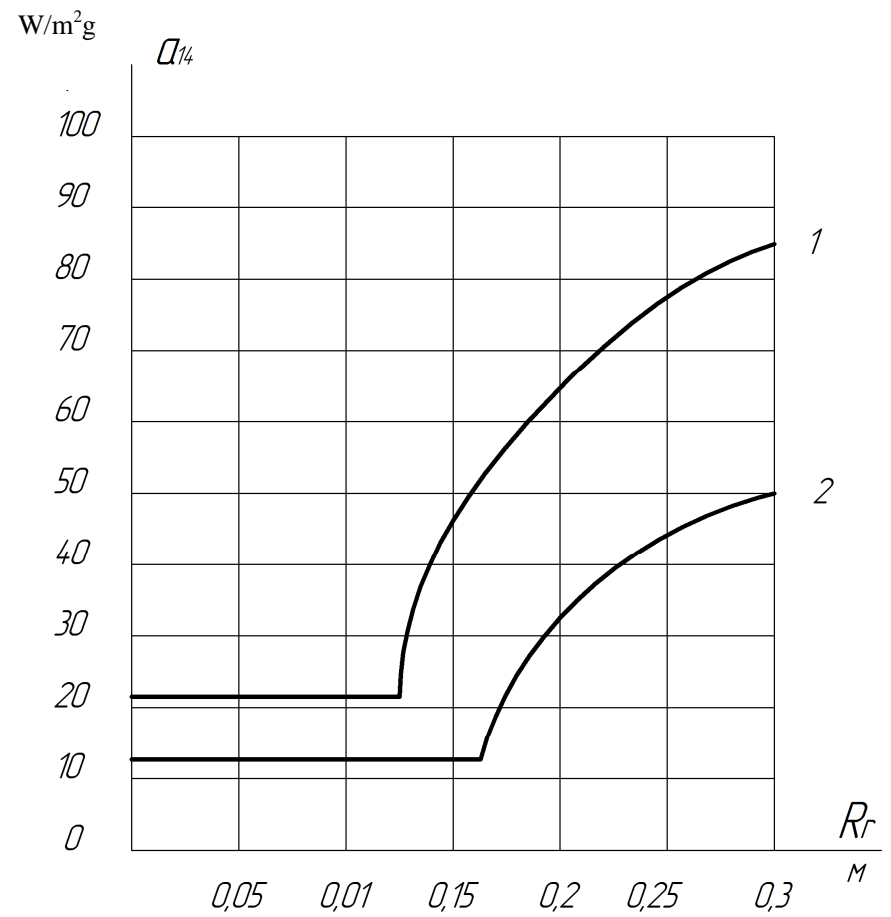

Fig. 5. Dependence of heat emission coefficient of machine rotor ends from rotor radius to air at different rotor $\mathrm{rpm}: 1) \mathrm{a}_{14}=\mathrm{f}\left(\mathrm{R}_{\mathrm{r}}\right)$ at $\left.\omega_{\mathrm{r}}=320 \mathrm{rad} / \mathrm{s} ; 2\right)$ $\mathrm{a}_{14}=\mathrm{f}\left(\mathrm{R}_{\mathrm{r}}\right)$ at $\omega_{\mathrm{r}}=150 \mathrm{rad} / \mathrm{s}$.

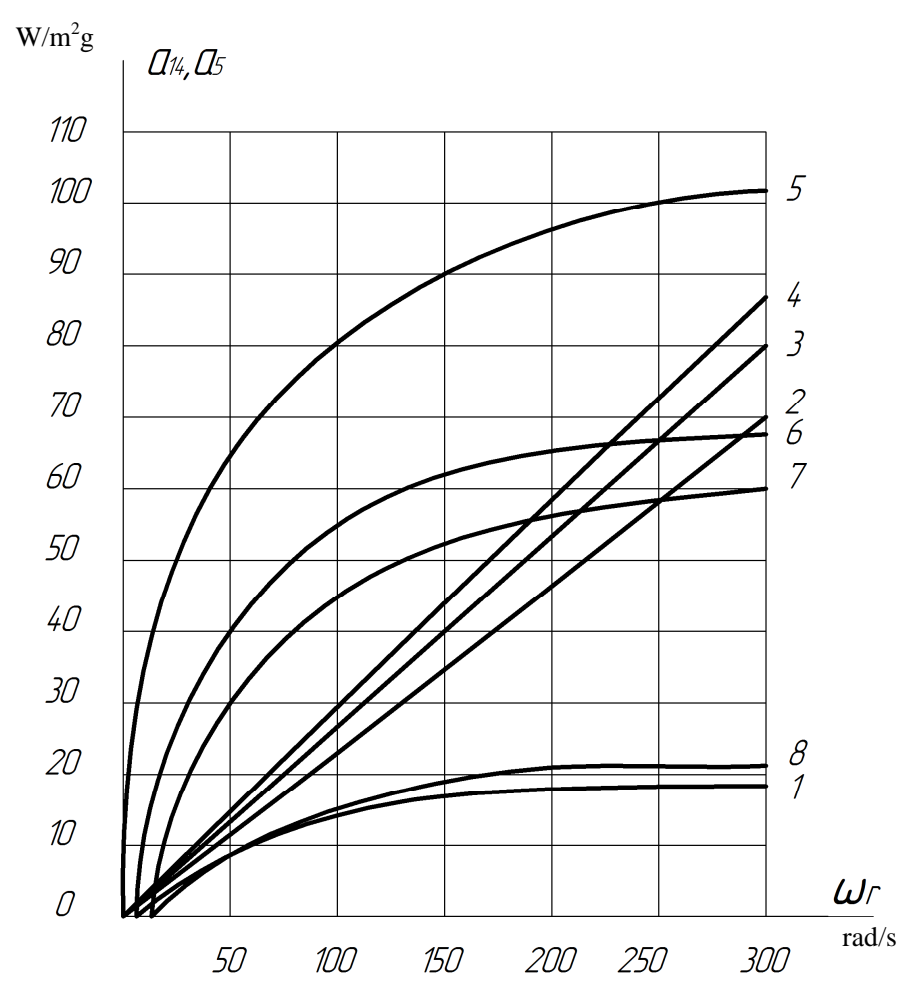

Fig. 6. Dependence of heat emission coefficient of rotor ends on rpm: 1) $\mathrm{a}_{14}=\mathrm{f}(\omega)$ at $\left.\mathrm{R}_{\mathrm{rot}}=0.15 \mathrm{~m} ; 2\right) \mathrm{a}_{14}=\mathrm{f}(\omega)$ at $\left.\mathrm{R}_{\mathrm{rot}}=0.2 \mathrm{~m} ; 3\right) \mathrm{a}_{14}=\mathrm{f}(\omega)$ at $\mathrm{R}_{\mathrm{rot}}=0.25 \mathrm{~m}$; 4) $\mathrm{a}_{14}=\mathrm{f}(\omega)$ at $\left.\mathrm{R}_{\mathrm{rot}}=0.3 \mathrm{~m} ; 5\right) \mathrm{a}_{5}=\mathrm{f}(\omega)$ for steel $\left.3 ; 6\right) \mathrm{a}_{5}=\mathrm{f}(\omega)$ for steel 20 ; 7 ) $a_{5}=f(\omega)$ for steel $\left.45 ; 8\right) a_{5}=f(\omega)$ for steel $16 \mathrm{KhN} 2$.
The analysis of curves $\alpha_{14}\left(R_{r}\right)$ at $\omega_{\mathrm{r}}=$ var in Fig. 5 allows determining the dependence regions of heat emission coefficient for solid rotor part on ratio of $R_{r}$ and $\omega_{r}$.

The dependencies of $\alpha_{14}\left(\omega_{\mathrm{r}}\right)$ at $\mathrm{R}_{\mathrm{r}}=\mathrm{var}$ and $\alpha_{5}\left(\omega_{\mathrm{r}}\right)$ for different grades of rotor steel and its dimensions are presented in Fig. 6.

\section{DETERMINATION OF HEAT EMISSION COEFFICIENTS IN WHOLE ROTOR}

As known, in the considered asynchronous motor, the rotor is a working member, in which a technological process proceeds. In this connection, the determination of the heat, which will be released by the rotor to the product is of great significance. To do this, one should know the expression for heat emission coefficient $\alpha_{11}$. Noteworthily, when discussing total rotor, we suggest the total rotor only in mechanical sense rather than in electromagnetic one.

When determining the heat emission coefficient in the rotor, the heat emission through wall $\delta_{4}$ should be neglected due to its negligibility.

In [9] the ring channels are designed with a due account for only lateral component of liquid flow velocity, while its twist is not considered.

The exploitation background proves the inconsistency of this statement at relatively small heads. In this connection, the liquid flow velocity is determined as some sum of two velocities $\mathrm{V}_{\text {prod }}$ and $\mathrm{V}_{\mathrm{tw}}$.

$$
\begin{gathered}
V_{\text {prod }}=\frac{G}{\rho_{l} \pi\left[R_{5}^{2}-\left(R_{5}-\delta_{1}\right)^{2}\right]} ; \\
V_{t w}=R_{5} \cdot \omega_{r} .
\end{gathered}
$$

To determine the heat emission coefficient $\alpha_{\mathrm{M}}$, let us determine the liquid flow kind from Reynolds number [6, 9].

$$
R e=\frac{\sqrt{V_{p r o d}^{2}+V_{t w}^{2} \cdot 2 \delta_{1}}}{v_{l}}
$$

at $\operatorname{Re} \leq 10^{4}$ the regime is laminar and $\alpha_{11}$ is determined as

$$
\alpha_{11}=\frac{0.1 \lambda_{l}\left(P_{r l}\right)^{0.4}}{\left(\delta_{1}\right)^{1.6}} \cdot 0.6 \text {. }
$$

at $\operatorname{Re}>10^{4}, \alpha_{11}$ is determined as

$$
\alpha_{11}=\frac{0.01 \lambda_{l} R e^{0.8}}{\delta_{1}}\left(P_{r l}\right)^{0.4} L
$$

where $\mathrm{L}$ is the equivalent rotor length determined by the ratio of $l$ and $\delta_{1}$ as in [10].

Fig. 7 depicts the dependencies of $\alpha_{11}(\omega)$ at $\mathrm{G}=\mathrm{V}_{\mathrm{ar}}$ and at $\mathrm{l}$ $=\frac{L_{e}}{2}$; in Fig. 8, $\alpha_{11}(\omega)$ at $l=\mathrm{V}_{\mathrm{ar}}$ and $\mathrm{G}=1000 \mathrm{~kg} / \mathrm{h}$. For the sake of comparison, the dependence of $\alpha_{11}(\omega)$ is given without due account for liquid twist in the ring channel. 


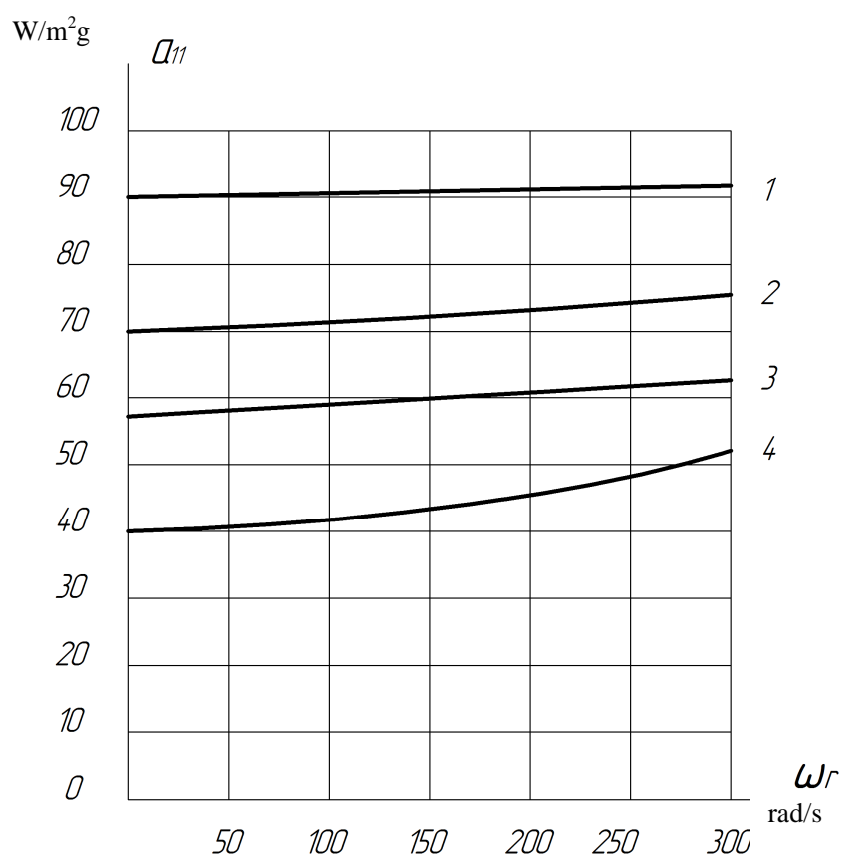

Fig. 7. Dependencies of heat emission coefficient in gap $\delta_{1}$ on rotor rpm at $\mathrm{G}=\mathrm{var}, \mathrm{l}=0.05 \mathrm{~m}$

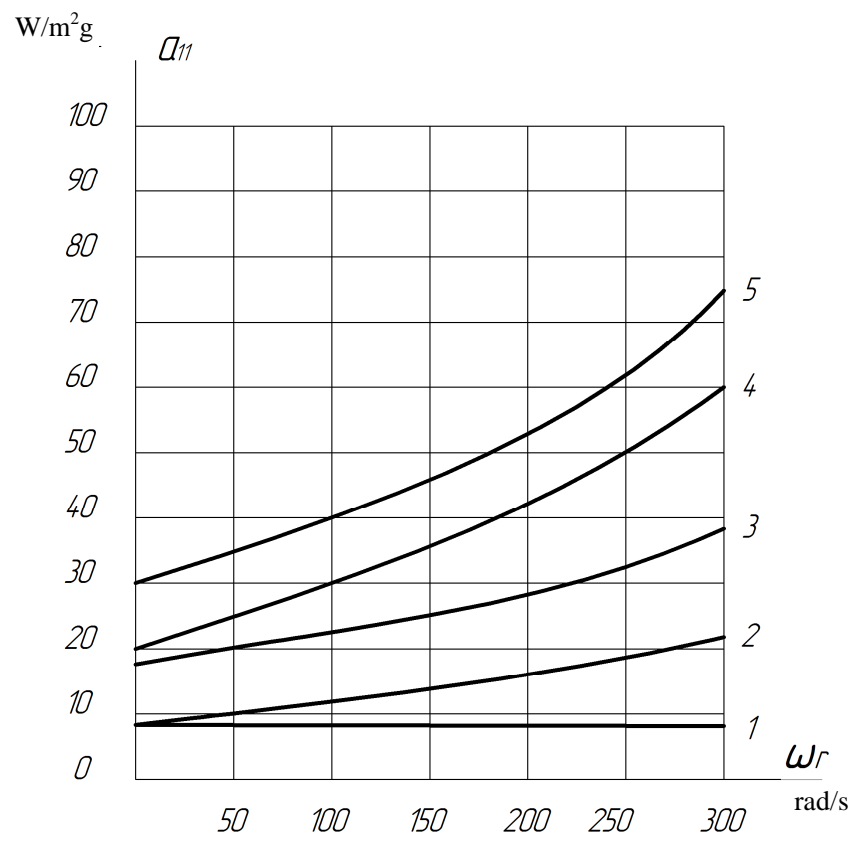

Fig. 8. Dependencies of heat emission coefficient in gap $\delta_{1}$ on rotor rpm in different rotor surface points at $\mathrm{G}=$ const, where 1 is lateral coordinate. 1) $l=0.025 \mathrm{~m}$ (not accounting for $\left.\omega_{\mathrm{r}}\right)$; 2) $l=0.025 \mathrm{~m}$; 3 ) $l=0.05 \mathrm{~m}$; 4) $l=0.075 \mathrm{~m}$; 5) $l=0.1 \mathrm{~m}$.

\section{References}

[1] V.N. Erikh, M.G. Rasina, M.G. Rudin, Chemistry and technology of oil and gas, Leningrad "Khimiya", 1977.

[2] Oil and gas separation. Retrieved from: http://infoneft.ru/index.php?action=full_article\&id=589

[3] O.F. Glagoleva, V.M.Kapustin, Oil processing technology (in Russian). 2 volumes. Vol. 1 Primary oil processing, Moscow: Khimiya, KolosS, 2007

[4] B.Kh. Gaitov, Ya.M. Kashin, L.E. Kopelevich, A.V. Samorodov, V.A. Kim Setup for oil separation, Oil industry, Vol. 7, pp. 90-92, 2017.

[5] B.Kh. Gaitov, Ya.M. Kashin, L.E. Kopelevich, A.V. Samorodov, V.A. Kim, P.V. Sereda, AER-Advances in Engineering Research, Vol. 133, pp. 350-356, 2017.

[6] A.V. Lykov Heat conductivity theory. Moscow: Higher school, 1967.

[7] M.A. Mikheev, I.M. Mikheeva, Heat transfer fundamentals. Moscow: Sergiya, 1977.

[8] V.V. Dombrovskiy', Z.M. Kuchinskaia, B.A. Reshko, Calculation of electromagnetic and heat phenomena under dynamic operation regimes of electrical machines, Problems of electrical machine dynamics, Omsk, pp. 42-47, 1987.

[9] L.A. Dorfman, Hydrodynamic resistance and heat emission of rotating bodies, Moscow: Press of physical and mathematical literature, 1960.

[10] G.P. Zedginidze, Measurement of temperature of rotating machine parts. Moscow: Mashgiz, 1962.

[11] G.G. Schastlivyi, Heating of closed asynchronous motors, Kiev: Naukova dumka, 1966. 